\title{
Sosialisasi dan Pendampingan Penggunaan Online Single Submission pada Pelaku Usaha Kecil dan Menengah di Kota Depok
}

\author{
Maya Puspita Dewi ${ }^{1, *}$, Tuswoyo ${ }^{2}$, Abdul Gofur ${ }^{3}$, Dony Hendarto ${ }^{4}$ \\ 1,2,3,4 Pascasarjana Institut Ilmu Sosial dan Manajemen STIAMI, Jakarta, Indonesia \\ ${ }^{1}$ maya.pd@stiami.ac.id* \\ * corresponding author
}

ARTICLE INFO

Keywords

OSS;

$U K M$;

Kota Depok;

\begin{abstract}
As an innovation, Online Single Submission is expected to guarantee the certainty of licensing which has been considered complicated and inefficient. In its development, electronic-based licensing did not work as expected. Lack of socialization and assistance for the Small and Medium Enterprises, has an impact on the low level of their understanding. The target activity is the Small and Medium Enterprises in Depok City. The activities went very well. The obstacle to this activity is the lack of supporting tools.
\end{abstract}

\section{PENDAHULUAN}

Terbitnya kebijakan berupa Peraturan Pemerintah Nomor 24 tahun 2018 tentang Sistem Pelayanan Perizinan Terintegrasi Berbasis Elektronik, atau yang lebih dikenal dengan Online Single Submission (OSS) bertujuan untuk menjamin efisiensi dan kemudahan pelayanan investasi di pusat dan di daerah. Dengan hadirnya kebijakan OSS ini, diharapkan bisa menjadi standar baru dalam tata kelola perizinan di negeri ini. Banyaknya perizinan yang hari ini menyebar dan berserakan di berbagai pusat layanan, hendak diintegrasikan ke dalam satu platform kebijakan nasional bernama OSS. Integrasi horizontal (antar Kementrian/Lembaga di tingkat pusat) ataupun vertikal (pusat dengan daerah) menjadi titik masuk bagi upaya-upaya lanjutan, termasuk sharing data, standardisasi bussines process, sampai pada tahap monitoring.

Sebagaimana diketahui bahwa OSS sebagai bentuk perizinan berbasis elektronik ini merupakan bagian dari e-government di bidang pelayanan publik yang digalakan pemerintah dalam sektor perizinan. Diharapkan dengan adanya OSS ini akan memberikan kepastian waktu, kepastian proses, dan kepastian biaya bagi pelaku usaha dalam mengajukan perizinan. Outcome dari sistem OSS ini adalah tumbuhnya iklim investasi di Indonesia. Harus diakui bahwa selama ini aspek perizinan yang berbelit-belit, lama, dan akhirnya berbiaya besar, menjadi salah satu faktor penghambat investasi.

E-Government diartikan sebagai "....the use by government agencies of information technologies (such as Wide Area Networks, the Internet, and mobile computing) that have the ability to transform relations with citizens, businesses, and other arms of government. (World Bank, 2002)"

E-Government bertujuan memberikan pelayanan tanpa adanya intervensi dari pemangku kepentingan. Dengan diberlakukannya e-government, maka diharapkan akan tercipta kepercayaan publik kepada pemerintah (Glyptis et al., 2020). Selain itu e-government juga bertujuan untuk mendukung good governance. Penggunaan teknologi yang mempermudah masyarakat untuk mengakses informasi dapat mengurangi korupsi dengan cara meningkatkan transparansi dan akuntabilitas lembaga publik (Santa, MacDonald, \& Ferrer, 2019). Dampak positif dari egovernment adalah memperluas partisipasi publik dimana masyarakat dimungkinkan untuk terlibat aktif dalam pengambilan keputusan/kebijakan oleh pemerintah (Ashaye \& Irani, 2019). 
Penerapan e-government memiliki banyak manfaat khususnya dalam menunjang efektivitas dan efisiensi dalam pelayanan publik. Manfaat-manfaat tersebut seperti diungkapkan oleh (Dash \& Pani, 2016) adalah:

\section{Mengurangi Biaya}

Memberikan pelayanan secara on-line atau dalam jaringan dapat secara signifikan mengurangi total biaya administrasi, relasi, dan interaksi yang dikeluarkan pemerintah maupun stakeholdernya dibandingkan pelayanan secara manual.

\section{Mendukung Perkembangan Ekonomi}

Teknologi dapat memudahkan pemerintahan dalam menciptakan iklim bisnis yang positif dengan menyederhanakan tahapan administrasi atau mengurangi birokrasi. Selain itu, terdapat dampak langsung terhadap ekonomi, misalnya seperti dalam e-procurement atau proses lelang secara elektronik dimana menciptakan kompetisi yang lebih luas dan lebih banyak peserta.

\section{Memperkuat Transparansi dan Akuntabilitas}

Implementasi e-government dapat meningkatkan transparansi, kontrol, dan akuntabilitas penyelenggaraan pemerintahan dalam rangka penerapan konsep Good Corporate Governance. egovernment membantu meningkatkan transparansi dalam proses pengambilan keputusan dengan penyediaan informasi serta pelacakan dalam jaringan (on-line tracking) yang mudah diakses oleh masyarakat.

4. Meningkatkan Pelayanan bagi Masyarakat

E-government dapat memberikan layanan yang lebih baik pada masyarakat dimana informasi dari pemerintah dapat dicari atau diperoleh tanpa harus secara fisik datang ke kantor-kantor pemerintahan. Bahan-bahan informasi tersebut tersedia dalam 24 jam sehari dan tujuh hari dalam seminggu tanpa harus bergantung pada jam operasional kantor-kantor pemerintah.

5. Meningkatkan Administrasi Publik

E-Government akan mengintegrasikan segala komponen yang berkaitan dengan system informasi, system manajemen sumber daya manusia, penganggaran, pengawasan, sehingga akan menjadikan proses administrasi publik yang lebih efisien.

6. Pemberdayaan Masyarakat

Pemberdayaan masyarakat dilaksanakan melalui informasi yang mudah diperoleh yang kemudian memungkinkan masyarakat dan pihak-pihak lain sebagai mitra pemerintah terlibat dalam proses pengambilan keputusan atau kebijakan publik secara merata dan demokratis.

Dalam perjalanannya, ternyata program yang digadang-gadang sebagai jalan keluar kemudahan berinvestasi ini belum maksimal penerapannya bahkan justru dianggap menyulitkan pelaku usaha dalam mendapatkan perizinan. Hal ini berdampak pada terhambatnya investasi terutana di daerah. Berdasarkan hasil evaluasi setahun pelaksanaan OSS yang dilakukan oleh Komisi Pemantauan Pelaksanaan Otonomi Daerah (KPPOD) terhadap kota/kabupaten yang ada di Indonesia, dapat ditarik kesimpulan bahwa implementasi program OSS belum efektif sebagaimana diharapkan. KPPOD pun menjelaskan bahwa salah satu penyebabnya adalah masih belum maksimalnya peran pemerintah daerah dalam memberikan pemahaman pada pelaku usaha mengenai penggunaan OSS dan masih tumpang tindihnya aturan yang ada di daerah juga menjadi faktor penghambat implementasi program nasional ini (KPPOD, 2020).

Kondisi tersebut terjadi pula di Kota Depok yang menjadi daerah penyangga Ibukota. Dengan segala fasilitas dan infrastruktur terkhnologi yang sudah mumpuni, ternyata masih mengalami hal serupa. Kondisi pelaku UKM di Kota Depok yang menjadi objek dalam kegiatan Pengabdian Kepada Masyarakat (PKM) ini secara umum memang belum memiliki pemahaman yang baik mengenai OSS. Jangankan memahami, ternyata pelaku UKM kebanyakan belum mengetahui program OSS, bagaimana penggunaannya, apa manfaat dan tujuannya. Padahal 
sebetulnya dengan sistem OSS ini segala proses perizinan diperlukan seharusnya menjadi lebih gampang karena sudah berbasis online dan terintegrasi.

Hal tersebut tentunya harus menjadi concern kita bersama sebagai akademisi yang merupakan bagian dari masyarakat untuk bersinergi membantu program pemerintah dalam hal penggunaan aplikasi perizinan usaha berbasis elektronik ini. Akademisi tentunya harus mengambil peran untuk membantu pemerintah kota/kabupaten, sebagai fasilitator yang menjembatani antara kebijakan pemerintah dan masyarakat. Point utama yang diangkat dalam kegiatan PKM ini adalah sosialisasi dan pendampingan penggunaan OSS pada pelaku UKM di Kota Depok. Dalam konteks ini akademisi menjalin kerjasama dengan dinas terkait yaitu Dinas Koperasi dan UMKM Kota Depok.

\section{PELAKSAAAN DAN METODE}

\section{Pelaksanaan}

Pelaksanaan kegiatan PKM berlangsung pada hari Sabtu, 15 Februari 2020 dari jam 08.00 WIB s.d 12.00 WIB. Adapun lokasi kegiatan di Aula Dinas Koperasi dan UKM Kota Depok, dengan dihadiri oleh Dinas UKM Kota Depok, akademisi dari Institut Ilmu Sosial dan Manajemen STIAMI sebanyak 3 orang, dan 20 orang pelaku UKM di Kota Depok baik yang sudah mempunyai badan hukum ataupun belum mempunyai badan hukum selaku peserta dalam PKM ini.

Narasumber dan pendamping dalam kegiatan PKM ini adalah :

1. Dinas Koperasi dan UKM Kota Depok

2. Dr. Maya Puspita Dewi,S.Sos.,M.Si (Dosen Pascasarjana Institut STIAMI)

3. Tim Dosen dari Institut Ilmu Sosial dan Manajemen STIAMI :

a) Abdul Gafur

b) Doni Hendarto

c) Mahasiswa Institut Ilmu Sosial dan Manajemen STIAMI

\section{METODE}

Kegiatan PKM ini menggunakan metode :

1. Ceramah

Metode ini dipilih untuk mensosialisasikan point-point penting mengenai OSS sebagai sebuah kebijakan dari pemerintah pusat, apa tujuan dan manfaatnya bagi pelaku UKM.

2. Pendampingan

Metode ini dipilih untuk membantu para peserta dalam hal ini pelaku UKM dalam mempraktekan aplikasi OSS.

Adapun langkah-langkah dalam kegiatan PKM ini meliputi :

1) Analisis terhadap UKM di Kota Depok dilihat dari aspek pengajuan izin berusaha.

2) Studi pustaka tentang kebijakan OSS.

3) Koordinasi dengan Dinas Koperasi dan UKM Kota Depok sebagai leading sector.

4) Persiapan alat untuk pendampingan peserta.

5) Penentuan waktu pelaksanaan dan lamanya kegiatan PKM bersama-sama tim pelaksana.

6) Persiapan materi yang akan disampaikan dalam kegiatan PKM.

\section{HASIL DAN PEMBAHASAN}

Kegiatan PKM ini terlaksana dengan baik dan lancar karena memang memiliki relevansi dengan kebutuhan peningkatan pemahaman dan keterampilan penggunaan OSS bagi para pelaku UKM di Kota Depok. Berdasarkan hasil survey sebelum pelaksanaan, peserta belum memahami mengenai OSS, dan memerlukan pendampingan dalam proses pengajuan perizinan melalui OSS. 
Agar tujuan PKM bisa efektif, maka dalam kegiatan ini dilakukan pendekatan klasikal dan individual. Pendekatan klasikal dilakukan pada saat pembekalan materi pengenalan tentang OSS sedangkan pendekatan individual dilakukan pada saat pendampingan penggunaan OSS.

Selama kegiatan berlangsung, berdasarkan intensitas tanya jawab yang muncul ternyata kegiatan PKM ini memberikan hasil sebagai berikut:

1. Adanya peninhgkatam pengetahuan dan pemahaman serta ketrampilan peserta mengenai penggunaan OSS.

2. Adanya peningkatan kesadaran peserta untuk segera melengkapi perizinan berusaha yang diperlukan.

3. Mempererat tali silaturahim antara pihak Institut Ilmu Sosial dan Manajemen STIAMI, Pemerintah Kota Depok, dan pelaku UKM di Kota Depok.

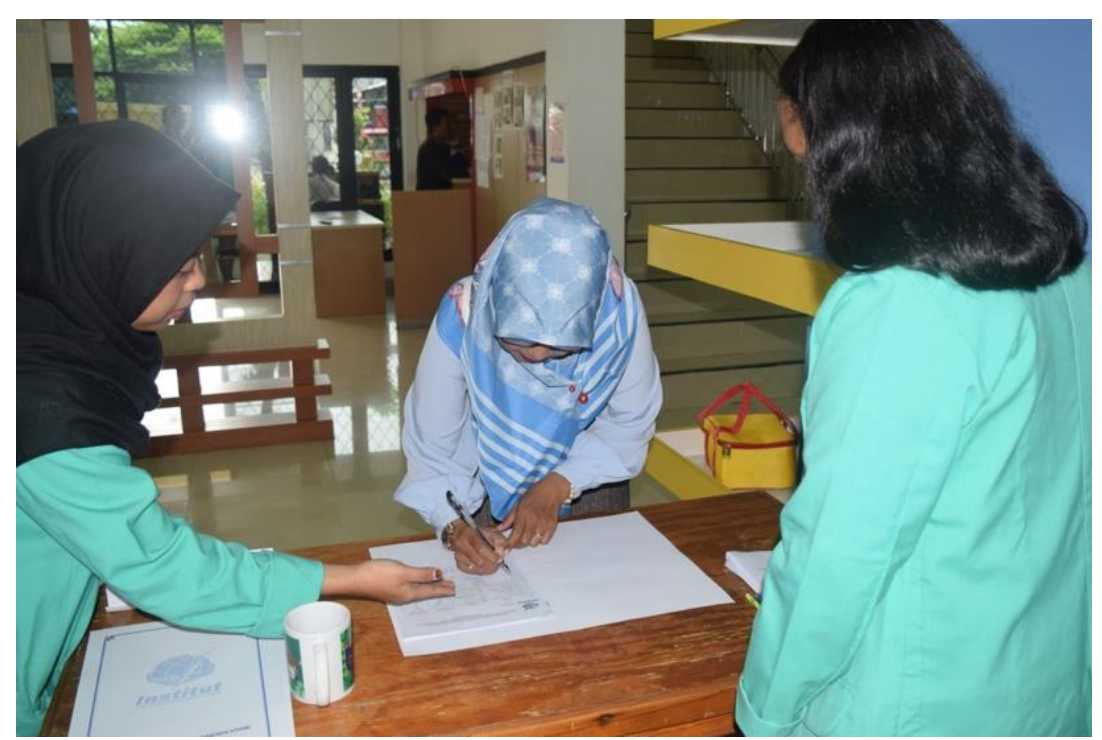

Gambar 1. Peserta sedang mengisi daftar hadir kegiatan PKM didampingi mahasiswa Institut STIAMI

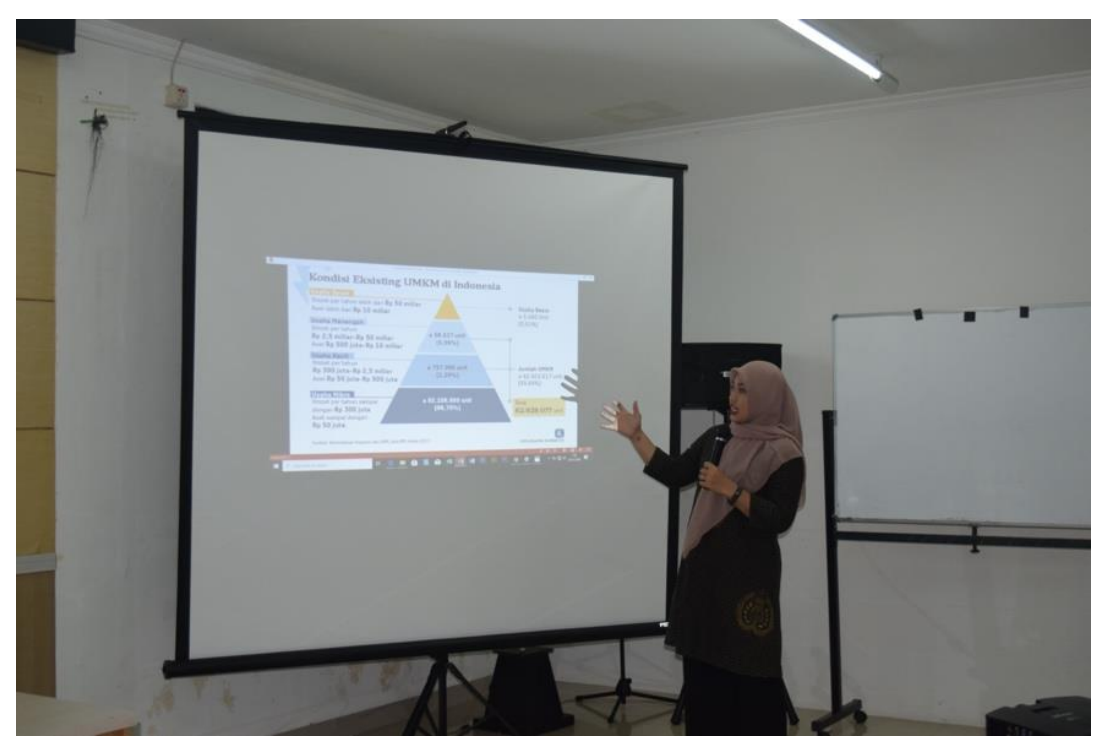

Gambar 2. Tim Dosen dari Institut STIAMI sedang memaparkan materi PKM 


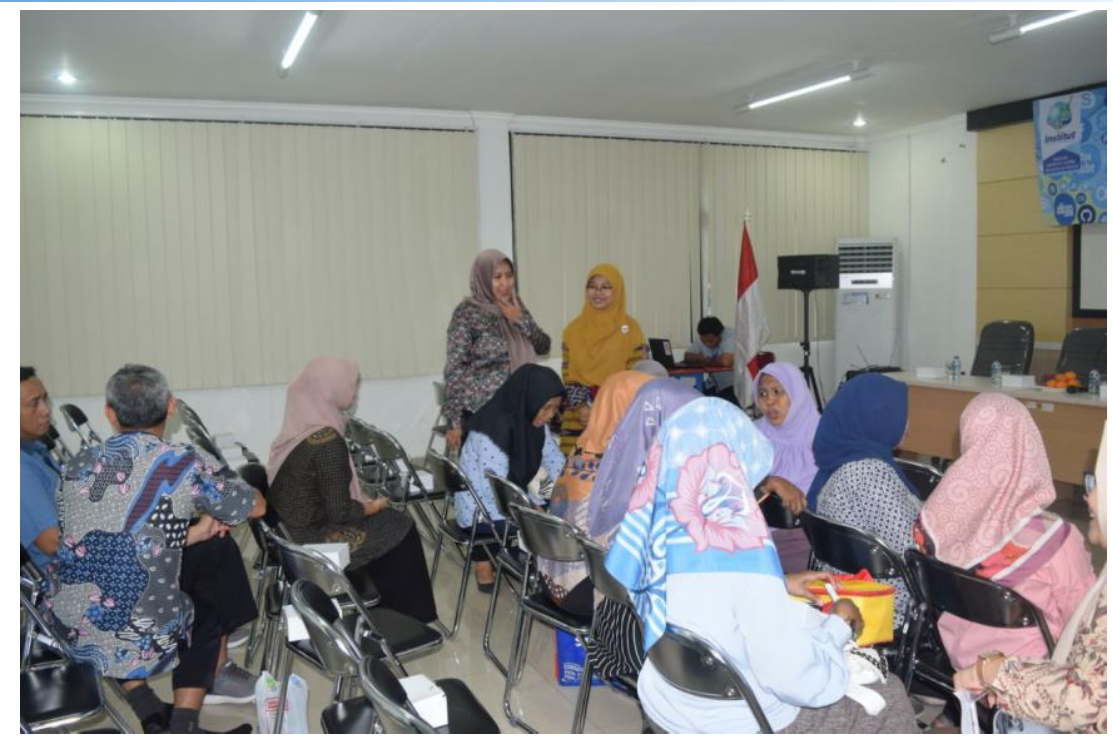

Gambar 3. Tim Dosen dari Institut STIAMI sedang melakukan pendampingan dengan menggunakan pendekatan individual.

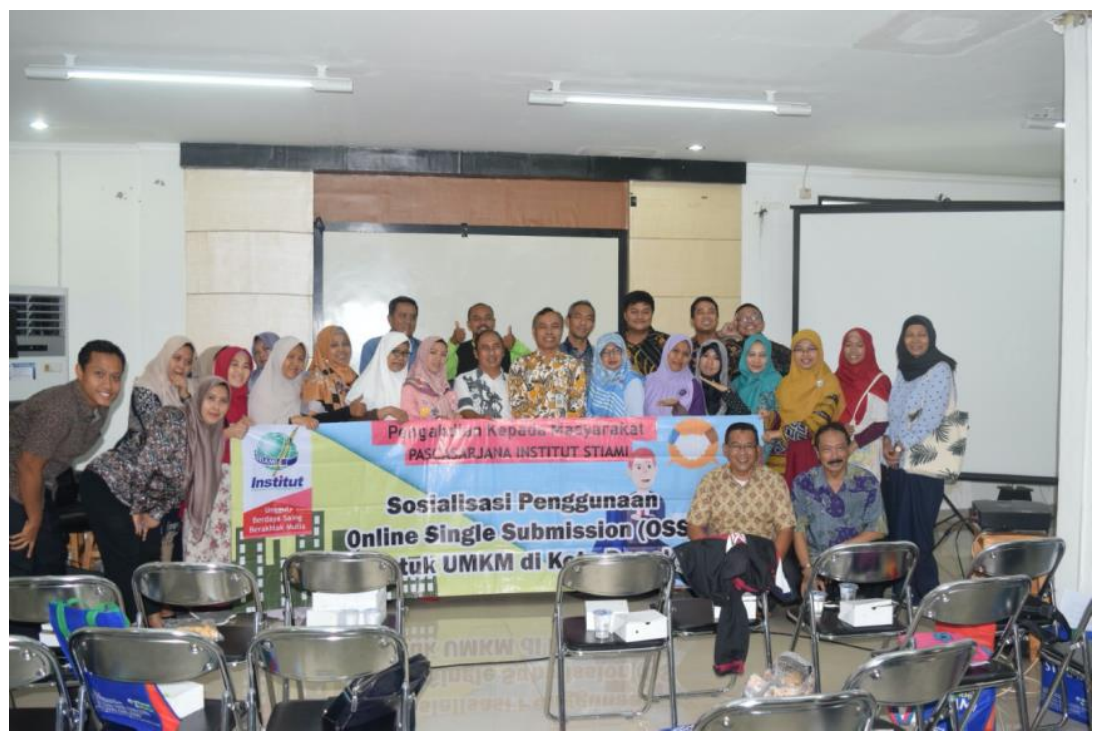

Gambar 4. Foto bersama setelah kegiatan.

Beberapa faktor yang mendukung terlaksananya kegiatan PKM ini adalah besarnya minat dan antusiasme peserta selama kegiatan. Sedangkan faktor-faktor yang menjadi penghambat keberhasilan kegiatan antara lain:

1. Keterbatasan waktu pelatihan.

2. Keterbatasan kemampuan peserta dalam penguasaan tekhnologi / gagap tekhnologi.

3. Keterbatasan alat-alat penunjang kegiatan, seperti proyektor untuk presentasi, alat peraga,Wifi, dan audio.

\section{KESIMPULAN DAN SARAN}

\section{Kesimpulan}

Secara umum, pelaksanaan kegiatan PKM ini berjalan dengan baik yang ditandai dengan keaktifan peserta untuk bertanya. Peserta mampu mengikuti kegiatan dan memahami materi yang disampaikan . Tingkat pemahaman peserta pun meningkat. Faktor curiosity yang tinggi dari peserta menjadi sebuah pendorong keberhasilan kegiatan PKM ini. Walau dalam beberapa hal terdapat kekurangan berkenaan dengan waktu dan media yang terbatas. 


\section{Saran}

Berdasarkan evaluasi yang dilakukan, saran untuk kegiatan selanjutnya adalah :

1. Bagi pihak Dinas Koperasi dan UKM, sebaiknya memfasilitasi WiFi di aula pertemuan.

2. Perlu diadakannya sustainable activity agar pelaku UKM di Kota Depok selalu mendapatkan informasi tentang kebijakan pemerintah terkait pelaku UKM.

\section{DAFTAR PUSTAKA}

Ashaye, O. R., \& Irani, Z. (2019). The role of stakeholders in the effective use of e-government resources in public services. International Journal of Information Management, 49(April), 253-270. https://doi.org/10.1016/j.ijinfomgt.2019.05.016

Dash, S., \& Pani, S. K. (2016). E-Governance Paradigm Using Cloud Infrastructure: Benefits and Challenges. Procedia Computer Science, 85(Cms), 843-855. https://doi.org/10.1016/j.procs.2016.05.274

Glyptis, L., Christofi, M., Vrontis, D., Giudice, M. Del, Dimitriou, S., \& Michael, P. (2020). EGovernment implementation challenges in small countries: The project manager's perspective. Technological Forecasting and Social Change, 152(September 2019). https://doi.org/10.1016/j.techfore.2019.119880

KPPOD. (2020). KPPOD Nilai Sistem OSS Masih Terkendala di Implementasi. Retrieved from https://www.kppod.org/berita/view?id=715

Santa, R., MacDonald, J. B., \& Ferrer, M. (2019). The role of trust in e-Government effectiveness, operational effectiveness and user satisfaction: Lessons from Saudi Arabia in e-G2B. Government Information Quarterly, 36(1), 39-50. https://doi.org/10.1016/j.giq.2018.10.007

World Bank. (2002). The E-Government Hanbook for Developing Nations Advisory Board. Center For Democracy Technology, World Bank. 